\title{
Assessment of the quality of primary care for the elderly according to the Chronic Care Model ${ }^{1}$
}

\author{
Líliam Barbosa Silva² \\ Sônia Maria Soares ${ }^{3}$ \\ Patrícia Aparecida Barbosa Silva ${ }^{4}$ \\ Joseph Fabiano Guimarães Santos ${ }^{5}$ \\ Lívia Carvalho Viana Miranda ${ }^{6}$ \\ Raquel Melgaço Santos ${ }^{7}$
}

\begin{abstract}
Objective: to evaluate the quality of care provided to older people with diabetes mellitus and/ or hypertension in the Primary Health Care (PHC) according to the Chronic Care Model (CCM) and identify associations with care outcomes. Method: cross-sectional study involving 105 older people with diabetes mellitus and/or hypertension. The Patient Assessment of Chronic Illness Care (PACIC) questionnaire was used to evaluate the quality of care. The total score was compared with care outcomes that included biochemical parameters, body mass index, pressure levels and quality of life. Data analysis was based on descriptive statistics and multiple logistic regression. Results: there was a predominance of females and a median age of 72 years. The median PACIC score was 1.55 (IQ 1.30-2.20). Among the PACIC dimensions, the "delivery system design/ decision support" was the one that presented the best result. There was no statistical difference between the medians of the overall PACIC score and individual care outcomes. However, when the quality of life and health satisfaction were simultaneously evaluated, a statistical difference between the medians was observed. Conclusion: the low PACIC scores found indicate that chronic
\end{abstract} care according to the CCM in the PHC seems still to fall short of its assumptions.

Descriptors: Health of the Elderly; Primary Health Care; Self Care; Outcome and Process Assessment (Health Care); Diabetes Mellitus; Hypertension.

\footnotetext{
${ }^{1}$ Paper extracted from Doctoral Dissertation "Qualidade do cuidado à pessoa idosa com diabetes e/ou hipertensão atendida na Atenção Primária à Saúde", presented to Escola de Enfermagem, Universidade Federal de Minas Gerais, Belo Horizonte, MG, Brazil. Supported by Fundação de Amparo à Pesquisa do Estado de Minas Gerais (FAPEMIG), Brazil and Coordenação de Aperfeiçoamento de Pessoal de Nível Superior (CAPES), Brazil. ${ }^{2}$ Doctoral student, Escola de Enfermagem, Universidade Federal de Minas Gerais, Belo Horizonte, MG, Brazil. Scholarship holder at Coordenação de Aperfeiçoamento Pessoal de Nível Superior (CAPES), Brazil.

${ }^{3} \mathrm{PhD}$, Associated Professor, Escola de Enfermagem, Universidade Federal de Minas Gerais, Belo Horizonte, MG, Brazil. ${ }^{4} \mathrm{PhD}$.

${ }^{5}$ PhD, Physician, Hospital Governador Israel Pinheiro, Belo Horizonte, MG, Brazil.

${ }^{6}$ MSc, RN, Centro de Saúde, Secretaria Municipal de Saúde, Belo Horizonte, MG, Brazil.

${ }^{7}$ Undergraduate student in Nursing, Escola de Enfermagem, Universidade Federal de Minas Gerais, Belo Horizonte, MG, Brazil.
}

\section{How to cite this article}

Silva LB, Soares SM, Silva PAB, Santos JFG, Miranda LCV, Santos RM. Assessment of the quality of primary care for the elderly according to the Chronic Care Model. Rev. Latino-Am. Enfermagem. 2018;26:e2987. [Access Available in: DOI: http://dx.doi.org/10.1590/1518-8345.2331.2987. 


\section{Introduction}

The progressive aging of the population has led to an increase in chronic conditions, especially diabetes mellitus and hypertension, the main primary causes of cardiovascular diseases on the world stage. These diseases were responsible for 14.4 million deaths in 2015 and 81.6 million years lost as disability-adjusted life years (DALY) worldwide(1). Failures in the management of these chronic conditions contribute to negative impacts on the health of the population, with more late complications, rehospitalizations and lower quality of life, as well as an economic burden on health systems and family structure ${ }^{(2)}$.

Given this scenario, the magnitude of problems associated with aging will depend a great deal on how healthy, or sick, or dependent on others, people will be in the extra years of life. This represents challenges to be overcome by the health sector in the search for an active and healthy aging(3), mainly in the area of Primary Health Care (PHC), considered a privileged locus for operationalization of actions aimed at health promotion and disease prevention.

In order to maintain the functionality of the elderly, it is essential to optimize the management of chronic conditions. This requires multidimensional strategies anchored in the concept of health conditions and with theoretical references related to patient-centered care ${ }^{(4-}$ 5), which is not always observed. Studies have shown a persistent care practice aimed at treating the conditions and events resulting from the exacerbation of chronic conditions, in a fragmented, episodic and reactive manner ${ }^{(6)}$. Such practice becomes an obstacle in the consolidation of the quality of care provided especially in the $\mathrm{PHC}^{(7-9)}$.

To fill this gap, the most appropriate health care model to guide the practice is the Chronic Care Model $(\mathrm{CCM})^{(10)}$. This model guides the provision of chronic care through productive interactions between active and informed users and proactive and prepared health teams. Therefore, the CCM challenges the status quo of traditional health programs and emphasizes the importance of rethinking and redesigning the clinical practice at the primary health level.

One of the instruments that measure the congruence between care measures and the CCM from the perspective of users is the Patient Assessment of Chronic Illness Care (PACIC)(11), which has been adapted to Brazilian Portuguese(6). The PACIC emphasizes interactions between users and providers of care, especially aspects of assisted self-care; it includes the users' evaluation of the frequency with which they are given opportunities to adhere to treatment in the last six months, to understand the care and support model and their participation in decision-making with respect to treatment, setting goals, support for problem solving, and contextualization of counseling, as well as their perception about the coordination of care and followup by the local team ${ }^{(6)}$. This questionnaire has also been considered sensitive to changes in chronic care provision, associated with other measures of productivity and system improvements, mainly with clinical and behavioral outcomes ${ }^{(12-14)}$.

In Brazil, the PACIC has been translated and adapted into Portuguese ${ }^{(6)}$, since the CCM has been incorporated by the Ministry of Health(15) into the "Strategic Action Plan to Tackle Noncommunicable Diseases (NCD) in Brazil 2011-2022" as a care model that should subsidize actions directed at the care of people who experience chronic health conditions.

In this sense, when considering the current movement of reorganization of health services around chronic care, it is still unclear to what extent the assistance to older people with diabetes mellitus and/or hypertension in PHC is aligned with the precepts of the Chronic Care Model from the perspective of the elderly themselves, and how this assistance relates to outcomes of the care provided to these individuals.

Despite the discussions undertaken so far, research assessing the quality of care from the perspective of users, especially the elderly, is still limited. Thus, this makes the present study timely. The search for quality of health care services in Brazil has received much attention from the Ministry of health, with particular emphasis on old individuals, taking into account the needs of this age group in the adjustment of public policies. As a matter of fact, the reorientation of health services, with the creation of a culture of chronic care and incorporation of proactive evidence-based care and strategies for improvement of quality, is one of the international recommendations for the Region of the Americas ${ }^{(16)}$.

In light of the above, and assuming that older people with higher PACIC scores present better care outcomes, the objective of this study was to evaluate the quality of care provided to older people with diabetes mellitus and/ or hypertension in Primary Health Care, according to the Chronic Care Model, from the perspective of the elderly. We sought specifically to identify associations between the overall PACIC score and the outcomes of the care provided in the sample studied.

\section{Method}

This cross-sectional study is part of the second phase of the population-based study "Aging and Renal Disease" (en-DoRen), whose overall objective in the 
first phase was to estimate the prevalence of nondialytic chronic kidney disease in older people in one of the nine health districts of Belo Horizonte, Minas Gerais, Brazil(17). The choice of this district was based on the fact that this had the highest absolute number of individuals aged 60 years or older $(n=44,801)$ at the moment of planning the first phase of the study.

The current analysis was performed with a subsample of the first phase of the en-DoRen study which met the following inclusion criteria: individuals aged 60 years or older; under follow-up of a Family Health team active in the Northwest Sanitary District for at least one year; diagnosed with diabetes mellitus, arterial hypertension or both, self-reported or confirmed by the electronic medical record; individual who responded to the PACIC questionnaire. Elderly patients with severe cognitive impairment (Mini Mental State Exam score - MEEM $\leq 9$ ) without a responsible person who could assist in the responses were excluded from the sample.

The en-DoRen study database identified 143 PHC users. Of this total, 118 elderly patients had a medical diagnosis of diabetes mellitus, hypertension or both, and were included in the current analysis. There was a loss of 13 people who did not respond to PACIC questionnaire due to death ( $n=4)$, change of address and unsuccessful telephone contact attempt ( $n=3)$, and lack of success to find the person at home after three unsuccessful attempts $(n=6)$. Therefore, the final sample of this study was composed of 105 older people.

It is noteworthy that these losses occurred due to the different chronology of approval from the Research Ethics Committee (REC) in the two phases of the enDoRen study: before the REC approval to start the second phase, 54 elderly had already completed the first phase, and therefore, these elderly had to be approached a second time and invited to respond to the PACIC questionnaire.

The method proposed by Lwanga and Lemeshow $^{(18)}$ was used for sample calculation, to verify whether the number of participants in the present study was enough to evaluate the quality of care provided by the primary level of health care. To this end, the average prevalence of good quality of care in PHC of $39.7 \%{ }^{(19-22)}$, an absolute precision of $10 \%$ (the mean standard deviation of the quality of care of the aforementioned studies was $20.4 \%$ ) and a significance level of $5 \%$ were considered, obtaining an estimated sample size of 92 individuals. Taking into account $10 \%$ of possible losses, the total estimated number was 101 individuals. Therefore, the sub-sample of this study was adequate to evaluate the quality of care in
PHC from the perspective of elderly diabetes mellitus and/or hypertension patients.

The data were collected from August 26, 2014, to November 1, 2016, in the homes of the elderly, by two nurses involved in the research and six previously trained undergraduate scholarship fellows.

Fieldwork involved the application of structured questionnaires and collection of blood and urine samples. Information on sociodemographic, clinical, anthropometric, and biochemical variables, quality of life, and quality of primary care from the perspective of the elderly (PACIC) were collected.

The PACIC consists of 20 questions distributed into five dimensions: patient activation (3 questions that evaluate the extent to which the individual was motivated and supported by health professionals to initiate changes), delivery system design/decision support ( 3 questions that assess whether the individual has received support with for example educative material and the extent to which he is satisfied with the care provided), goal setting/tailoring (5 questions that evaluate the extent to which general instructions and suggestions have been adapted to the person's individual situation), problem solving/contextual (4 questions that refer to how health professionals deal with problems that interfere with the achievement of predefined objectives), follow-up/coordination ( 5 questions that address how often and how consistently the whole process has been conducted). Individuals can give only one answer to each question whose alternatives are on a 5-point Likert scale, namely: 1 ) almost never, 2) generally not, 3) sometimes, 4) most of the time, and 5) almost always(6).

The mean overall PACIC score is obtained by the sum of the scores of each question, divided by the total number of questions ( $n=20$ ). In turn, the dimension scores represent the mean scores of the questions in each particular dimension. Higher scores indicate the perception, from the part of users, of greater involvement in self-care and greater support for the care of their chronic conditions(6).

It should be emphasized that this questionnaire has been adapted and validated semantically and culturally by several groups interested in its use as a support tool for the diagnosis, adjustment, monitoring and evaluation of models of care to chronic conditions grounded in the Chronic Care Model, which has been tested in subjects with various chronic conditions, e.g. diabetes mellitus ${ }^{(11-14,23-24)}$ and cardiovascular diseases $^{(23,25)}$.

Blood pressure and anthropometric data were measured within an interval of up to two weeks after the home visit for application of the questionnaire. 
On this occasion, the collection of biological material (blood and urine) was scheduled for a maximum period of one week and guidelines were provided for the preparation of the test. The collection of biological material was performed in the morning by two members of the project, after a 12-hour fasting of the patient. The material was sent to a particular clinical laboratory for processing.

The dependent variables in this study were the overall score and the scores of each PACIC dimension.

The following variables were analyzed: sex (female, male); age in years; level of education in term of complete years of schooling (0-4 and 5 or more); monthly income categorized according to the minimum wage in force in the year of the interview; presence of formal or informal caregiver; polypharmacy (using five or more medications with the presentation of recent medical prescription); smoking (non-smoker, ex-smoker and current smoker); alcoholism measured by the Alcohol Use Disorders Identification Test-Consumption (AUDIT-C) questionnaire ${ }^{(26)}$ (scores $\geq 4$ for males and $\geq$ 3 for females suggest likely abuse of alcohol); physical activity (practice some sort of physical activity with a frequency of $\geq 3$ time/week and for $\geq 30$ minutes each session); self-reported morbidities confirmed in the electronic medical record; cognitive level assessed by the MMSE, with cutting point adjusted according to the instructional level of the elderly(27) (altered cognitive level indicated by scores $\leq 13$ in the case of illiterates; scores $\leq 8$ years in the case of literates with $\leq 8$ years of schooling; scores $\leq 26$ in the case of literates with $>8$ years of schooling); functional capacity assessed by the Katz index ${ }^{(28)}$ (scores 0-2: important dependence; 3-4: partial dependence; 5-6: independence); body mass index based on the cut-off points established for the elderly according to literature ${ }^{(29)}$ (underweight: $<22 \mathrm{~kg} / \mathrm{m}^{2}$; eutrophy: $22-$ $27 \mathrm{~kg} / \mathrm{m}^{2}$; overweight: $27-30 \mathrm{~kg} / \mathrm{m}^{2}$ for men and $27-$ $32 \mathrm{~kg} / \mathrm{m}^{2}$ for women; obesity: $>30 \mathrm{~kg} / \mathrm{m}^{2}$ for men and $>32 \mathrm{~kg} / \mathrm{m}^{2}$ for women); pressure levels categorized later into good control ( $<140 / 90 \mathrm{mmHg}$ in hypertensive and $<130 / 80 \mathrm{mmHg}$ in diabetics); self-perception of quality of life (categorized into "good/very good" and "bad/very bad/reasonable") and satisfaction with the own health (categorized into "satisfied/very satisfied" and "dissatisfied/very dissatisfied/neither satisfied nor dissatisfied"), obtained through the two first questions of the World Health Organization Quality of Life-bref (WHOQOL-bref) questionnaire, version translated and validated for Portuguese ${ }^{(30)}$. The biochemical variables collected were glycated hemoglobin (HbA1c), total cholesterol and fractions, triglycerides, fasting glucose, albumin/creatinine ratio (ACR), and serum creatinine.
Biochemical parameters were classified within the range of normality and considered in the analysis of care outcomes of elderly people with diabetes mellitus and/or hypertension: serum creatinine $(<1.3 \mathrm{mg} /$ $\mathrm{dL}$ in men and $<1.2 \mathrm{mg} / \mathrm{dL}$ in women), $\mathrm{ACR}(<30.0$ $\mathrm{mg} / \mathrm{g}), \mathrm{HbA} 1 \mathrm{c}(<7 \%$ in diabetics and $<6.5 \%$ in hipertensive), fasting glucose ( $<126 \mathrm{mg} / \mathrm{dL})$, total cholesterol ( $<200 \mathrm{mg} / \mathrm{dL}$ ), high density lipoprotein cholesterol/HDL-c ( $>40 \mathrm{mg} / \mathrm{dL}$ in men and $>50 \mathrm{mg} /$ $\mathrm{dL}$ in women), low density lipoprotein cholesterol/ LDL-c ( $<160 \mathrm{mg} / \mathrm{dL})$, and triglycerides ( $<150 \mathrm{mg} / \mathrm{dL}$ ). Glomerular filtration rate (GFR) was estimated by the Chronic Kidney Disease Epidemiology Collaboration creatinine equation and CKD was defined as GFR $<60$ $\mathrm{ml} / \mathrm{min} / 1.73 \mathrm{~m}^{2}$ and / or presence of albuminuria (ACR $\geq 30 \mathrm{mg} / \mathrm{g}$ ), confirmed in two laboratory tests with a time interval of $\geq 3$ months, according to the criteria for definition of CKD proposed by the Kidney Disease group: Improving Global Outcomes(31).

Data were analyzed using the Statistical Package for Social Sciences (SPSS, version 23.0, Chicago, IL, USA). First, the results were analyzed by means of descriptive techniques, expressed in proportions or percentages in the case of the categorical variables, and medians with respective interquartile ranges (IQ) in the case of non-parametric continuous variables. Normality was tested by the Kolmogorov-Smirnov test. The reliability of the PACIC was analyzed using the Cronbach's alpha coefficient. The Spearman'sRho test of the PACIC total score was used to test the correlation between the five dimensions of the questionnaire.

Medians of the overall PACIC scores were compared with care outcomes (biochemical parameters, body mass index, pressure levels and the two WHOQOL-bref questions used) by the $U$ Mann-Whitney test and later adjusted for potential confounding variables (sex, age, schooling, income, time of diagnosis of diabetes mellitus and time of diagnosis of arterial hypertension) in the multivariate model through Backward logistic regression. The significance level adopted was 5\%, rejecting the null hypotheses of the absence of differences when the $\mathrm{p}$-value was less than 0.05 . The values obtained were expressed in odds ratio (OR) and their respective $95 \%$ confidence intervals ( $95 \% \mathrm{CI})$.

The study was approved by the Research Ethics Committee of the Federal University of Minas Gerais (Opinion no 1,238,099) and by the Municipal Health Department of Belo Horizonte (Opinion no 1,351,378), observing all legal procedures. Participants were informed about the objectives of the study and 
signed the Informed Consent term, guaranteeing confidentiality and anonymity.

\section{Results}

The sample consisted of 105 elderly individuals, with a predominance of females $(67.6 \%)$. The age ranged from 60 to 93 years, with a median of 72.0 years (IQ 66.5-80.5 years). Low schooling was predominant among the participants (56.2\% reported 0 to 4 complete years of schooling). Just over $1 / 4$ of the sample reported a monthly income of $\leq 1$ minimum wage. The presence of a caregiver was reported by $11.4 \%$ of the sample. Regarding behavioral habits, $10.5 \%$ of the elderly were smokers, $19.0 \%$ had a probable diagnosis of alcohol abuse, and only $20.0 \%$ practiced some type of physical activity.

The majority of the elderly had a good or very good perception of quality of life (65.0\%) and was satisfied or very satisfied with their health (57.3\%). Altered cognitive levels were present in $10.5 \%$ of the elderly, and two of them presented a score $\leq$ 9 points in the MMSE and were under the care of a caregiver. Regarding activities of daily living, only $1.9 \%$ of the elderly had partial or total dependence. There was a high prevalence of dyslipidemia (86.7\%), CKD (30.5\%) and heart disease (20.0\%), and 13.3\% reported previous cerebrovascular accident. Only $28.6 \%$ of the elderly were eutrophic and $21.9 \%$ were obese. Among the hypertensive elderly ( $\mathrm{n}=$ $104), 42.9 \%$ had a concomitant diagnosis of diabetes mellitus. The median duration of hypertension was 13 years (IQ 7.0-23.0 years) and of diabetes mellitus was 7.0 years (IQ 4.0-13.0 years). Polypharmacy was present in $65.7 \%$ of the elderly.

Metabolic control and blood pressure levels were adequate in $74.3 \%$ and $54.3 \%$ of the elderly, respectively. Among the biochemical parameters investigated, the worst indicator was HDL_c (50.5\%), followed by triglycerides (65.0\%) and total cholesterol $(71.0 \%)$. Detailed information on care outcomes in the sample studied is presented in Table 1.

The reliability of the PACIC questionnaire was satisfactory according to the Cronbach's alpha coefficient (0.881). There was also a moderate to strong correlation between the five PACIC dimensions and the overall PACIC score, ranging from 0.490 (patient activation) to 0.889 (goal setting/tailoring), all statistically significant $(p<0.001)$.

The elderly attributed a low median score to the quality of care received according to the overall PACIC score (1.55; IQ 1.30-2.20). As for dimensions, it was observed that the delivery system design/decision support presented a better result (2.33, IQ 1.50-3.00), while Patient activation (1.00, IQ 1.00-1.67), Problem solving/contextual (1.00, IQ 1.00-2.00) and Follow-up/ coordination (1.60; IQ 1.00-2.00) stood out as frailties from the perspective of the elderly (Figure 1).

Table 1 - Care outcomes among older people with diabetes mellitus and/or hypertension followed-up in the Primary Health Care system. Belo Horizonte, MG, Brazil, 2014-2016

\begin{tabular}{|c|c|c|}
\hline Outcomes measures & & \\
\hline Perception of overall quality of life* & $\mathrm{n}$ & $\%$ \\
\hline Good/very good & 67 & 65.0 \\
\hline Neither bad nor good/bad/very bad & 36 & 35.0 \\
\hline \multicolumn{3}{|l|}{ Satisfaction with health* } \\
\hline Satisfied/very satisfied & 59 & 57.3 \\
\hline $\begin{array}{l}\text { Neither satisfied nor dissatisfied/ } \\
\text { dissatisfied/very dissatisfied }\end{array}$ & 44 & 42.7 \\
\hline \multicolumn{3}{|l|}{ Body mass index $\left(\mathrm{kg} / \mathrm{m}^{2}\right)$} \\
\hline$<22$ & 11 & 10.5 \\
\hline $22-27$ & 30 & 28.6 \\
\hline 27-30 (Males) and 27-32 (Females) & 41 & 39.0 \\
\hline$>30$ (Males) and > 32 (Females) & 23 & 21.9 \\
\hline Pressure levels & Median & Q25 - Q75† \\
\hline Systolic blood pressure $(\mathrm{mmHg})$ & 130.00 & $120.00-140.00$ \\
\hline Diastolic blood pressure $(\mathrm{mmHg})$ & 74.00 & $70.00-80.00$ \\
\hline \multicolumn{3}{|l|}{ Biochemical parameters } \\
\hline Fasting glucose $(\mathrm{mg} / \mathrm{dL})$ & 100.00 & $88.00-115.0$ \\
\hline $\mathrm{HbA} 1 \mathrm{c}^{\ddagger}(\%)$ & 6.10 & $5.65-6.80$ \\
\hline Total Cholesterol $(\mathrm{mg} / \mathrm{dL})^{\S}$ & 182.50 & $164.00-206.75$ \\
\hline LDL-c $\|(m g / d L)^{\pi}$ & 106.00 & $87.00-128.00$ \\
\hline $\mathrm{HDL} \mathrm{C}^{* *}(\mathrm{mg} / \mathrm{dL})^{\pi}$ & 45.00 & $40.00-54.00$ \\
\hline Triglycerides $(\mathrm{mg} / \mathrm{dL})^{\S}$ & 126.50 & $97.25-171.75$ \\
\hline Albumin/creatinine ratio $(\mathrm{mg} / \mathrm{g})$ & 8.05 & $3.73-15.98$ \\
\hline Serum creatinine $(\mathrm{mg} / \mathrm{dL})$ & 0.86 & $0.70-1.01$ \\
\hline $\begin{array}{l}\text { Glomerular filtration rate } \\
\left(\mathrm{mL} / \mathrm{min} / 1.73 \mathrm{~m}^{2}\right)^{\dagger+}\end{array}$ & 74.76 & $61.55-87.21$ \\
\hline
\end{tabular}

Note: * Two cases of missing information; + Q - quartile; $\neq$ HbA1c glycated hemoglobin; § Five cases of missing information; || LDL_c - low density lipoprotein cholesterol; I Six cases of missing information; ** HDL_c - high density lipoprotein cholesterol; †† Glomerular filtration rate estimated by the Chronic Kidney Disease Epidemiology Collaboration creatinine equation.

Regarding the answers to each item in the questionnaire, it was observed that more than half of the elderly mentioned "almost never" in response to 16 out of the 20 evaluated items, where the items 1 and 9 had the highest concentration of respondents $(89.5 \%$ and $94.3 \%$ ). Only item 5 presented a predominance of the "almost always" response (36.2\%) (Figure 2).

No statistical difference was observed between the medians of the overall PACIC score and individual care outcome indicators (Figure 3 ), even after adjusting for sex, age, schooling, income, time of diagnosis of diabetes mellitus and time of diagnosis of hypertension. However, when the median differences 
in overall PACIC scores were evaluated among the elderly who reported good or very good quality of life and those who were satisfied or very satisfied with their health, a statistically significant difference was found between medians ( 1.83 vs. $1.40, p=0.019$ ), adjusted for the aforementioned variables. These elderly people were 2.01 times more likely to have higher total median PACIC scores than the other elderly patients $(\mathrm{OR}=2.01,95 \% \mathrm{CI}: 1.12-3.59, \mathrm{p}=$ 0.019) (data not shown).

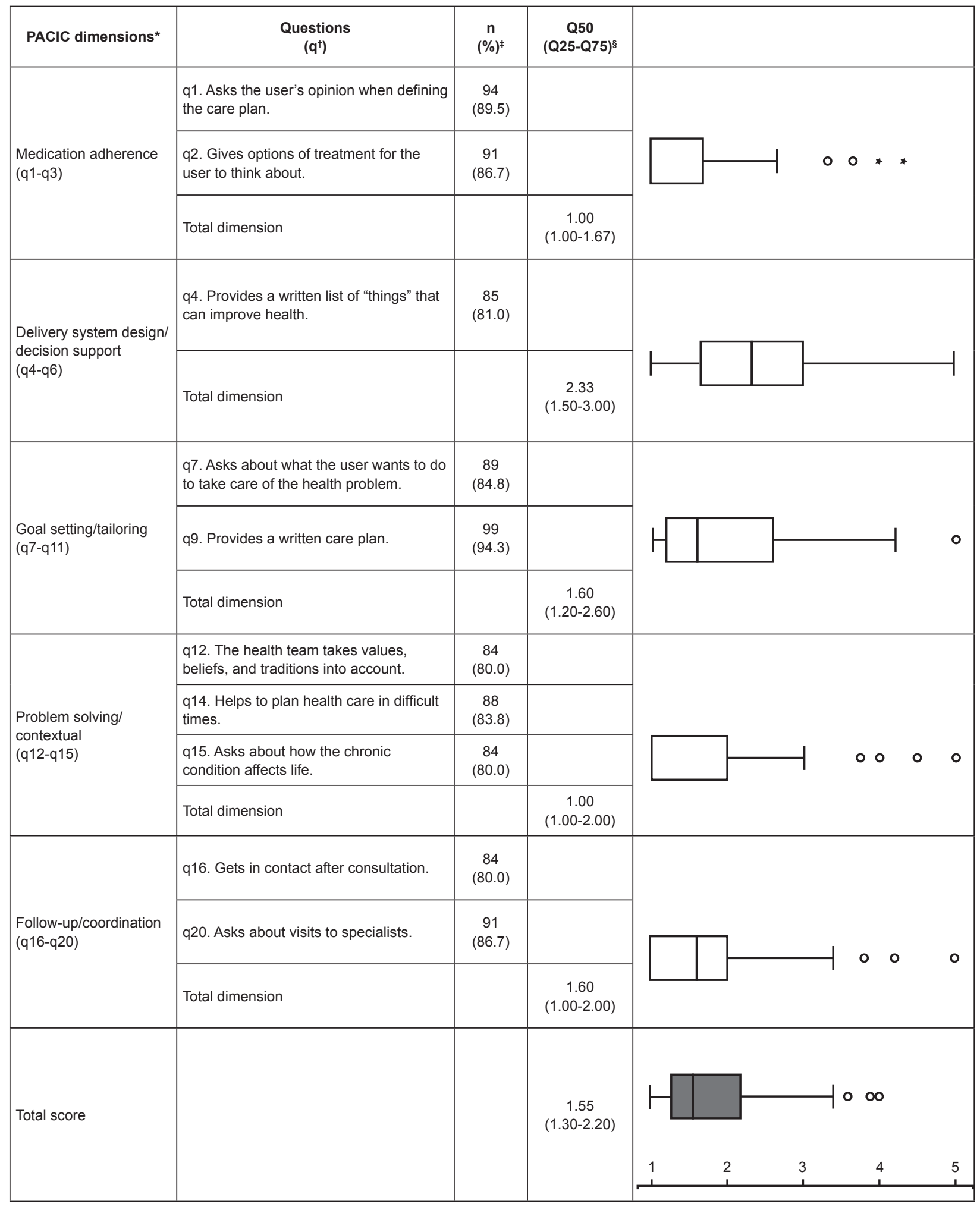

Note: Likert-type scale from 1 to 5 ( 1 = lowest agreement, 5 = highest congruence with the Chronic Care Model - CCM). It was decided to highlight the 10 questions with the lowest evaluation among the 20 evaluated items. * PACIC - Patient Assessment of Chronic Illness Care; $+\mathrm{q}-$ question; $\neq$ Percentage of people who answered "almost never"; § Q - quartile.

Figure 1 - Descriptive distribution of the 10 items with the worst evaluation and the overall score and boxplots of the five dimensions of the Patient Assessment of Chronic Illness Care. Belo Horizonte, MG, Brazil, 2014-2016 


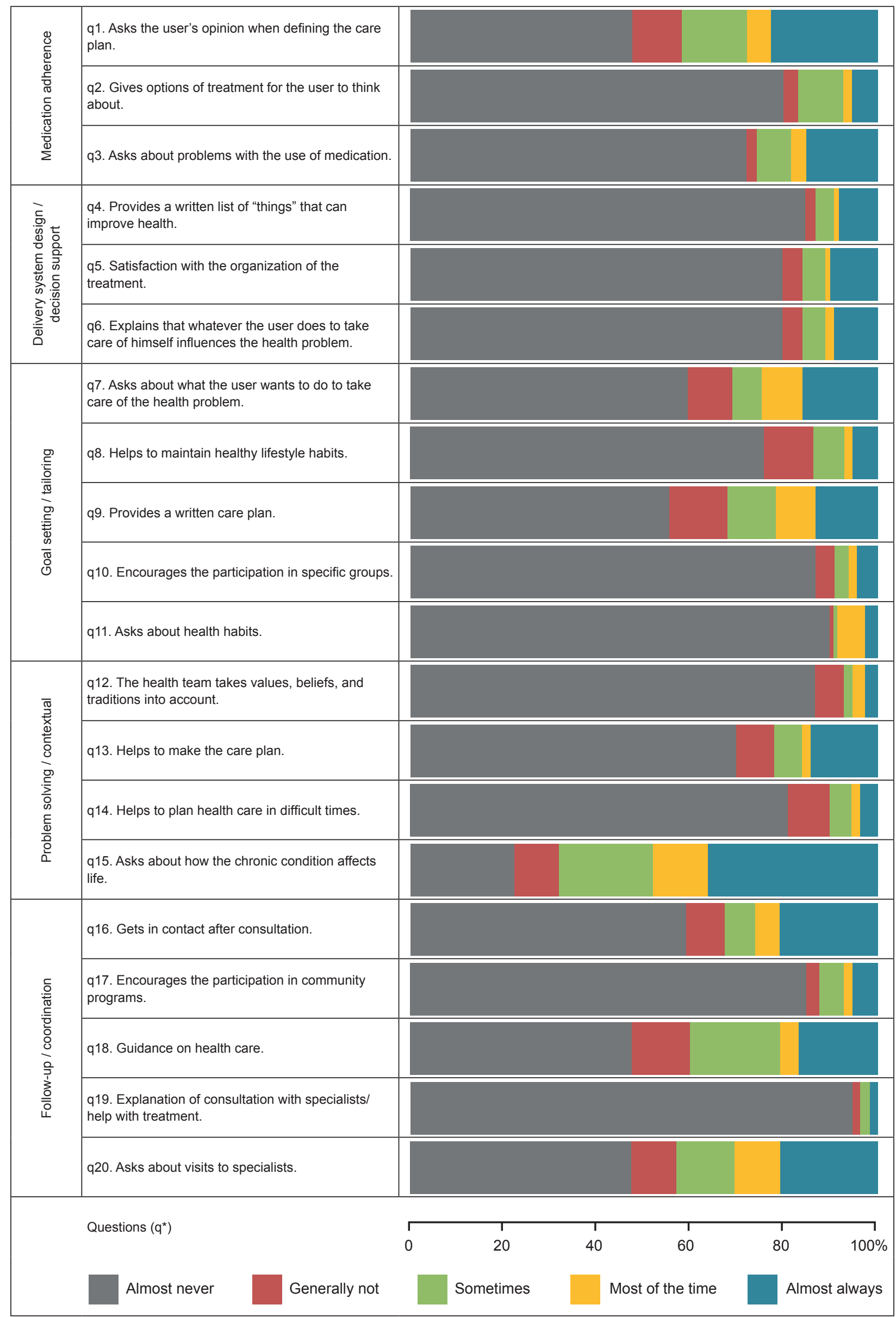

Note: $* \mathrm{q}$ - question.

Figure 2 - Descriptive distribution of the five dimensions of the Patient Assessment of Chronic Illness Care (PACIC) for each question. Belo Horizonte, MG, Brazil, 2014-2016 


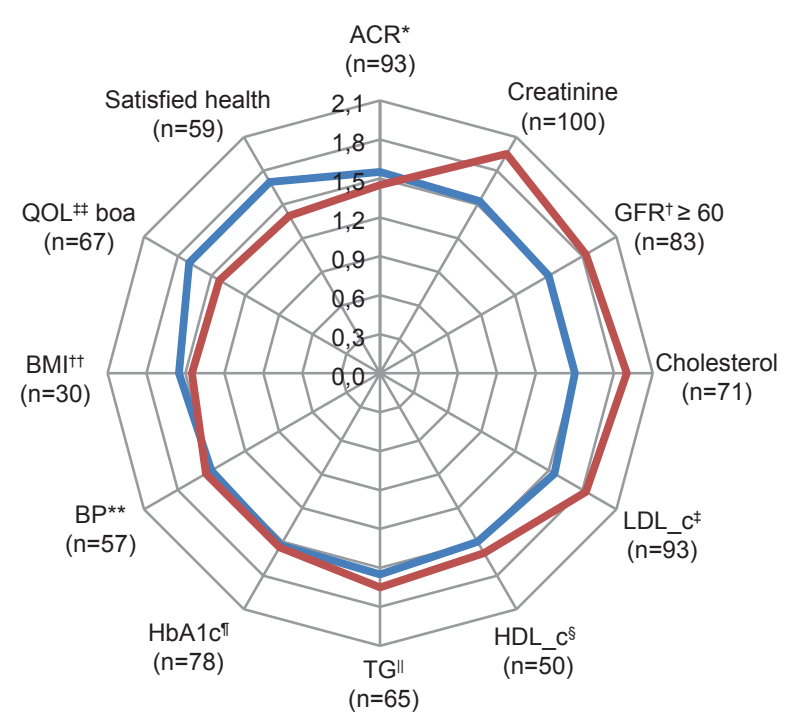

Care outcomes

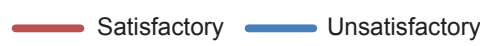

Note: * ACR - Albumin/creatinine ratio; + GFR - glomerular filtration rate; $\neq$ LDL_c - low density lipoprotein cholesterol; § HDL_c - high density lipoprotein cholesterol; II TG - triglycerides; ๆ - HbA1c - glycated hemoglobin; ** BP - blood pressure; †† BMI - body mass index; $¥ \neq \mathrm{QOL}$ - quality of life. $n=$ number of elderly people with satisfactory care outcome. Controlled HbA1c: $<7 \%$ (diabetic) and $<6.5 \%$ (hypertensive). Controlled BP: $<140 / 90 \mathrm{mmHg}$ (hypertensive) and $<130 / 80 \mathrm{mmHg}$ (diabetics). p>0.05 adjusted for sex, age, schooling, income, time of diagnosis of diabetes mellitus and time of diagnosis of hypertension.

Figure 3 - Median of the total scores of the Patient Assessment of Chronic Illness Care (PACIC) according to satisfactory or unsatisfactory care outcomes. Belo Horizonte, MG, Brazil, 2014-2016

\section{Discussion}

In this study, the overall PACIC score of 1.55 indicates that, in general, the congruence between the assessed care process and the CCM never occurred or occurred few times from the perspective of the participants. This result contrasts with other international studies that reached a total score higher than that presented in the current research, ranging from 2.33 to $4.19^{(12-14,23-25,32)}$. The only study at the national level, the one responsible for the translation of the questionnaire in the country, in Curitiba, reported a mean score of $2.86^{(6)}$. Part of this difference can be explained by the fact that the cited studies included younger people with other morbidities. Another relevant aspect is the possible influence of the presence of greater cultural homogeneity in other countries when compared to the Brazilian reality.

The low score found suggests weaknesses of Family Health teams in ensuring proactive, planned, coordinated and patient-centered care ${ }^{(6)}$. These flaws are reflected in possible difficulties in incorporating non-clinical aspects of chronic care into the practice, as for example, the implementation of assisted self-care ${ }^{(16)}$.

This is one of the key elements of the CCM to ensure a high quality of care. The Pan-American Health Organization considers a fundamental and innovative strategy to assist people with chronic health problems. Once the chronic condition is diagnosed, either diabetes mellitus or hypertension, the patient will need to deal with this condition in the daily life and, consequently, self-care will be a life-long task for the patient and his family(16). To emphasize the importance of self-care, we stress that people with diabetes mellitus spend about 8.7 hours per year with a health professional, and during the other 8,751.3 hours, they manage the illness by themselves. Therefore, it is imperative to help these individuals understand and take on the responsibility for their illness( ${ }^{(33)}$.

By definition, assisted self-care consists of the systematic implementation of education and support interventions by health professionals in order to increase the users' ability and confidence in managing their health problems, promoting a sense of coresponsibility. It includes the choice of problems to be prioritized, fixation and monitoring of the fulfillment of goals focused on the needs, values, and preferences of the user, identifying the difficulties to fulfill them, support for the solution of problems based on a care plan constructed with the user, among other actions. This way, care providers are no longer prescribers but become partners of people who use health care systems $^{(16)}$.

Based on the above, questions about the training of health professionals are raised, as this may not give proper emphasis to a care approach that recognizes the crucial role of users in managing their own health condition. This questioning is shared by other authors ${ }^{(24)}$ and it is supported in the literature. A research developed in Quebec with 364 diabetes mellitus, hypertension and chronic obstructive pulmonary disease patients (mean age: $64.9 \pm 11.8$ years), users of educational institutions, found on the one hand a mean overall PACIC score of 2.8 and, on the other hand, a high quality of the technical care with almost $80 \%$ of adherence to the clinical guidelines for the chronic conditions studied. The authors explained that this fact may have occurred in part by the academic context itself, whose clinical teaching, that it is focused on training, may direct less attention on the implementation of actions aligned with the CCM's benchmarks than on technical quality, which is more easily evaluated(23).

However, the low PACIC scores may also indicate that, even if these actions have been implemented 
in practice, they are not adding value to people, because they were not recognized by users. This is because although the term self-care is well inserted in the discourse of the health education field, its exact understanding and authentic application do not always occur so easily because it often implies a paradigm shift. Complementing what has already been commented, traditional biomedical health care models directed to acute and episodic conditions often support the formation and socialization of health professionals, so that when these professionals try to incorporate their principles into their current beliefs and practices, many misconceptions about the subject arise. Thus, professionals need to become aware of such contradictions and undertake changes of attitude or philosophy ${ }^{(34)}$.

In turn, when analyzing each individual PACIC item, it was found that only four questions obtained medians above 1.00 (q5, q8, q10, and q11). However, only q5 "Were you satisfied with the organization of your treatment" obtained a score above the average of the total possible score to be scored, with a predominance of the "almost always" response $(36.2 \%)$, with the proviso that $21.9 \%$ of the elderly said they were "almost never" satisfied. The contrast between the low scores of the other questions with greater satisfaction with the health service should be interpreted with caution, since it is possible that the elderly in this study have higher expectations regarding the health care received and this, consequently, influences the perception of the quality of care offered by the Family Health teams. Future research should explore in greater depth the relationship between quality of care and satisfaction in this population segment.

Among questions with high percentages of "almost never" answers, we highlight q1 (Asks the user's opinion when defining the care plan - 89.5\%), q2 (Gives options of treatment for the user to think about - $86.7 \% \%$ ), q7 (Asks about what the user wants to do to take care of the health problem - 84.8\%) and q12 (The health team takes values, beliefs and traditions into account when indicates the treatment - 80.0\%). This finding is worrisome since it evidences possible failure of health professionals in recognizing the responsibility of users to make decisions about their own care. In this perspective, the lack of flexibility in care choices may lead to the idea, although implicitly, that the individual will have his life controlled by the disease. This situation in the context of elderly people with diabetes mellitus and/or hypertension can lead to unfavorable clinical and functional outcomes, insofar as the metabolic consequences are a function of the decisions and actions that people make during the daily management of the illness ${ }^{(34-35)}$.

This is because the discovery of a chronic condition requires that people change their daily life so as to be able to organize the care, from the development of skills to handle a range of activities whether or not predicted by medical knowledge, including adverse conditions for the control of the disease imposed by the socio-cultural context in which the patient is inserted, a situation called by some authors as "rupture of the biography of the individual". However, over time(36), patients may develop an attitude of "strategic lack of adherence", unconsciously and critically failing to comply with medical recommendations( ${ }^{(36)}$. In this sense, some strategies aimed at supporting effective self-care can be used by Family Health teams. They are, for example, "behavioral strategies" (empowerment - discovery and development of the individuals' capacity, valuing their autonomy and responsibility for their own life; "support groups", "problem solving"; "motivation and support for autonomy")(36).

Regarding the factors associated with the PACIC, the results did not support the hypothesis that older people with higher PACIC scores present better care outcomes. However, in the joint analysis of the questions related to the perception of quality of life and satisfaction with health, the hypothesis was upheld. These findings indicate the need to re-signify the practice beyond technical and laboratory care to maintain high levels of quality of care.

The findings demonstrate that it is important to highlight the important role of Nursing in $\mathrm{PHC}$ as a driving force for change. Its essence, the "care", provides spaces of intersubjective encounter between professionals and the persons who experience chronic health conditions so necessary for the development of attitudes/behavioral changes. It is a slow and difficult process for people with chronic conditions, as it involves rethinking the whole routine and adapting the life project. In this sense, the performance of nurses has great potential to act according to the precepts of chronic care, be it in the nursing consultation, or in individual or collective educational activities, and even in mobilization actions in the community. This can be achieved through a critical-reflexive assimilation of knowledge that makes it possible to arise awareness of the new health condition in an autonomous way. In this context, Nursing is able to rescue the intersubjectivity, involving reflection and action, allowing to the others to problematize their situation. Freedom starts filling the space previously inhabited by the persons' dependence and in this way 
they discover how to participate in the transformation of their world towards the integral health of the human being(37).

As limitations of the study, we highlight the crosssectional nature of the study that makes it impossible to determine causal relationships of the outcome and variables of interest. There were also no national or international studies that included only elderly people using public health services for comparison purposes, and the bias of selective response cannot be excluded. As potentialities of the study, we highlight a population-based and randomized sample among the census sectors; the use of a questionnaire that has been translated and adapted to Portuguese, contributing to the accuracy of the answers given in the assessment of the quality of care; and the absence of missing cases in the PACIC questionnaire, which the literature indicates that can reach up to $32.7 \%(25,32)$.

\section{Conclusion}

Poor quality of care provided for older people with diabetes mellitus and/or hypertension was found in the Primary Health Care according to the Chronic Care Model from the perspective of the elderly. This indicates that the reorganization of the care model oriented towards chronic care in the context of PHC seems still to fall short of its precepts, giving way to traditional biomedical models, from the perspective of the study participants.

It was not possible to confirm the hypothesis that older people with higher PACIC scores present better care outcomes, only in the case of older people who reported good or very good quality of life and who were simultaneously satisfied or very satisfied with health.

We recommend the expansion of strategies in loco that make it possible the diversification of prevention and management actions of health conditions that include the culture, values, and experiences of users.

\section{References}

1. GBD 2015 DALYs, HALE Collaborators. Global, regional, and national disability-adjusted life-years (DALYs) for 315 diseases and injuries and healthy life expectancy (HALE), 1990-2015: a systematic analysis for the Global Burden of Disease Study 2015. Lancet. [Internet]. 2016 Oct [cited Feb 15, 2017];388(10053):1603-58. Available from: https://www.ncbi.nlm.nih.gov/pmc/ articles/PMC5388857/pdf/main.pdf

2. Grandy S, Fox KM. Change in health status (EQ-5D) over 5 years among individuals with and without type
2 diabetes mellitus in the SHIELD longitudinal study. Health Qual Life Outcomes. [Internet]. 2012 Aug [cited Jan 17, 2017];10:99. Available from: https://www.ncbi. nlm.nih.gov/pmc/articles/PMC3490883/pdf/1477-752510-99.pdf

3. Berlezi EM, Farias AM, Dallazen F, Oliveira KR, Pillatt AP, Fortes CK. Analysis of the functional capacity of elderly residents of communities with a rapid population aging rate. Rev Bras Geriatr Gerontol. [Internet]. 2016 Aug [cited Sept 14, 2017];19(4):643-52. Available from: http://www.scielo.br/pdf/rbgg/v19n4/1809-9823-r bgg-19-04-00643.pdf

4. Koley M, Saha S, Ghosh S, Nag G, Kundu M, Mondal $\mathrm{R}$, et al. Patient-Assessed Chronic Illness Care (PACIC) scenario in an Indian homeopathic hospital. J Tradit Complement Med. [Internet]. 2016 Jan [cited Apr 11, 2017];6(1):72-7. Available from: https://www.ncbi. nlm.nih.gov/pmc/articles/PMC4765762/

5. Nasmith L, Kupka S, Ballem P, Creede C. Achieving care goals for people with chronic health conditions. Can Fam Physician. [Internet]. 2013 Jan [cited Feb 10, 2017];59(1):11-3. Available from: https://www.ncbi. nlm.nih.gov/pmc/articles/PMC3555640/

6. Schwab GL, Moysés ST, Kusma SZ, Ignácio SA, Moysés SJ. Perception of innovations in Chronic Diseases/Conditions' care: an evaluative research in Curitiba. Saúde Debate. [Internet]. 2014 Oct [cited Apr 2, 2017];38(special):307-18. Available from: http:// www.scielo.br/pdf/sdeb/v38nspe/0103-1104-sdeb-38spe-0307.pdf

7. Al-Khaldi YM. Quality of diabetic care in family practice centre, Aseer Region, Saudi Arabia. J Health Spec. [Internet]. 2014 July/Sept [cited Sept 14, 2017]; 2(3):109-13. Available from: http://www.thejhs.org/ temp/JHealthSpec23109-3539346_094953.pdf

8. Jingi AM, Nansseu JR, Noubiap JJ. Primary care physicians' practice regarding diabetes mellitus diagnosis, evaluation and management in the West region of Cameroon. BMC Endocr Disord. [Internet]. 2015 Apr [cited Sept 14, 2017];15:18. Available from: https://www.ncbi.nlm.nih.gov/pmc/articles/ PMC4403824/pdf/12902_2015_Article_16.pdf

9. Noubiap JJN, Jingi AM, Veigne SW, Onana AE, Yonta EW, Kingue $S$. Approach to hypertension among primary care physicians in the West Region of Cameroon: substantial room for improvement. Cardiovasc Diagn Ther. [Internet]. 2014 Oct [cited Sept 14, 2017];4(5):35764. Available from: https://www.ncbi.nlm.nih.gov/pmc/ articles/PMC4221322/pdf/cdt-04-05-357.pdf

10. Wagner EH. Chronic disease management: what will it take to improve care for chronic illness? Eff Clin Pract. [Internet]. 1998 Aug/Sept [cited Apr 19, 2017];1(1):2- 
4. Available from: https://ecp.acponline.org/augsep98/ cdm.pdf

11. Glasgow RE, Wagner EH, Schaefer J, Mahoney LD, Reid

RJ, Greene SM. Development and validation of the Patient Assessment of Chronic Illness Care (PACIC). Med Care. [Internet]. 2005 May [cited Dec 2, 2016];43(5):43644. Available from: https://www.familycarenetwork. com/sites/default/files/Development\%20and\%20 Validation\%20of\%20PACIC.pdf

12. Aung E, Donald M, Coll J, Dower J, Williams GM, Doi SAR. The impact of concordant and discordant comorbidities on patient-assessed quality of diabetes care. Health Expect. [Internet]. 2015 Oct [cited May 2, 2017];18(5):1621-32. Available from: https://www. ncbi.nlm.nih.gov/pmc/articles/PMC5060868/pdf/HEX18-1621.pdf

13. Casillas A, Iglesias K, Flatz A, Burnand B, Peytremann-Bridevaux I. No consistent association between processes-of-care and health-related quality of life among patients with diabetes: a missing link? BMJ Open Diabetes Res Care. [Internet]. 2015 [cited May 12, 2017];3(1):e000042. Available from: http://drc.bmj. com/content/bmjdrc/3/1/e000042.full.pdf

14. Chiu HC, Hsieh HM, Lin YC, Kuo SJ, Kao HY, Yeh $\mathrm{SC}$, et al. Patient assessment of diabetes care in a pay-for-performance program. Int J Qual Health Care. [Internet]. 2016 Apr [cited May 12, 2017];28(2):18390. Available from: https://academic.oup.com/intqhc/ article-lookup/doi/10.1093/intqhc/mzv120

15. Malta DC, Oliveira TP, Santos MAS, Andrade SSCA, Silva MMA, Grupo Técnico de Monitoramento do Plano de DCNT. Progress with the Strategic Action Plan for Tackling Chronic Non-Communicable Diseases in Brazil, 2011-2015. Epidemiol Serv Saúde. [Internet]. 2016 Apr/June [cited Sept 12, 2017];25(2):373-90. Available from: http://www.scielo.br/pdf/ress/v25n2/2237-9622ress-25-02-00373.pdf

16. Pan American Health Organization. Innovative care for chronic conditions: organizing and delivering high quality care for chronic noncommunicable diseases in the Americas. Washington, DC: PAHO; 2013. 103 p. [Internet]. [cited Jan 20, 2017]. Available from: https://www.google.com.br/url?sa=t\& $r c t=j \& q=\& e s r c=s \&$ source $=$ web\&cd $=2 \& c a d=r j a \& u a c t=$ 8\&ved=0ahUKEwi39qTwzY3UAhVCDpAKHXc9AscQFggu MAE\&url=http\%3A\%2F\%2Fwww.paho.org\%2Fhq\% 2 Findex.php\%3Foption \% 3 Dcom_docman \% 26task\%3Ddoc_download\%26gid\%3D21115\%26Item id\%3D270\%26lang\%3Den\&usg=AFQjCNGXRdMidtZZF Gx_-EAI3go_2kgcVA

17. Silva LB, Silva PAB, Soares SM, Santos JFG, Santos FC, Santos RM, et al. Prognóstico e fatores associados à consciência da doença renal crônica em idosos. J Bras
Nefrol. [Internet]. 2016 [cited Feb 13, 2017];38(3 Suppl 1):273. Available from: http://www.jbn.org.br/article/ list/38/3\%20Suppl\%201/2016

18. Naing NN. Determination of sample size. Malays J Med Sci. [Internet]. 2003 July [cited Feb 13, 2017];10(2):84-6. Available from: https://www.ncbi. nlm.nih.gov/pmc/articles/PMC3561892/

19. Araújo LUA, Gama ZAS, Nascimento FLA, Oliveira HFV, Azevedo WM, Almeida HJB Júnior. Evaluation of the quality of primary health care from the perspective of the elderly. Ciênc saúde coletiva. [Internet]. 2014 Aug [cited May 12, 2017];19(8):3521-32. Available from: http://www.scielo.br/pdf/csc/v19n8/1413-8123csc-19-08-03521.pdf

20. Augusto DK. Fatores associados aos atributos da Atenção Primária à Saúde avaliados por idosos que não possuem plano privado de saúde, residentes na Região Metropolitana de Belo Horizonte, em 2010. [Dissertação - Mestrado em Saúde Coletiva]. Belo Horizonte: Centro de Pesquisas René Rachou; 2016 [cited Apr 13, 2017]. Available from: https://www.arca.fiocruz.br/bitstream/ icict/16386/2/Disserta\%C3\%A7\%C3\%A30_EPI_ DanielKnuppAugusto.pdf

21. Martins AB, D'Avila OP, Hilgert JB, Hugo FN. Primary healthcare geared to the needs of the elderly: from theory to practice. Ciênc Saúde Coletiva. [Internet]. 2014 Aug [cited Feb 17, 2017];19(8):3403-16. Available from: http://www.scielo.br/pdf/csc/v19n8/1413-8123csc-19-08-03403.pdf

22. Oliveira EB, Bozzetti MC, Hauser L, Duncan BB, Harzheim E. Assessing the quality of care for the elderly in services from public primary health care in Porto Alegre, Brazil. Rev Bras Med Fam Comunidade. [Internet]. 2013 Oct/Dec [cited Jan 15, 2017];8(29):264-73. Available from: http://www.lume.ufrgs.br/bitstream/ handle/10183/140034/000913344.pdf?sequence $=1$

23. Houle J, Beaulieu MD, Lussier MT, Grande C, Pellerin JP, Authier M, et al. Patients' experience of chronic illness care in a network of teaching settings. Can Fam Physician. [Internet]. 2012 Dec [cited Jan 15, 2017];58(12):136673. Available from: https://www.ncbi.nlm.nih.gov/pmc/ articles/PMC3520666/pdf/0581366.pdf

24. Lévesque JF, Feldman DE, Lemieux $V$, Tourigny A, Lavoie JP, Tousignant P. Variations in Patients' Assessment of Chronic Illness Care across organizational models of primary health care: a multilevel cohort analysis. Healthc Policy. [Internet]. 2012 Nov [cited Jan 13, 2017];8(2):e108-23. Available from: https://www. ncbi.nlm.nih.gov/pmc/articles/PMC3517876/pdf/policy08-e108.pdf

25. Tusek-Bunc K, Petek-Ster M, Ster B, Petek D, Kersnik J. Validation of the Slovenian version of patient assessment of chronic illness care (PACIC) in 
patients with coronary heart disease. Coll Antropol. [Internet]. 2014 June [cited Feb 17, 2017];38(2):437-

44. Available from: https://www.ncbi.nlm.nih.gov/ pubmed/25144971

26. Bush K, Kivlahan DR, McDonell MB, Finn SD, Bradley KA. The AUDIT Alcohol Consumption Questions (AUDIT-C): an effective brief screening test for problem drinking. Ambulatory Care Quality Improvement Project (ACQUIP). Alcohol Use Disorders Identification Test. Arch Intern Med. [Internet]. 1998 Sept [cited Feb 16, 2017];158(16):1789-95. Available from: http:// jamanetwork.com/journals/jamainternalmedicine/ fullarticle/208954

27. Bertolucci PHF, Brucki SMD, Campacci SR, Juliano Y. The Mini-Mental State Examination in an outpatient population: influence of literacy. Arq Neuropsiquiatr. [Internet]. 1994 [cited Feb 16, 2017];52(1):1-7. Available from: http:// www.scielo.br/pdf/anp/v52n1/01.pdf

28. Duarte $Y A O$, Andrade $C L$, Lebrão ML. Katz Index on elderly functionality evaluation. Rev Esc Enferm USP. [Internet]. 2007 June [cited Feb 16, 2017];41(2):31725. Available from: http://www.scielo.br/pdf/reeusp/ v41n2/20.pdf

29. Lipschitz DA. Screening for nutritional status in the elderly. Prim Care. [Internet]. 1994 Mar [cited Dec 14, 2016];21(1):55-67. Available from: https://www.ncbi. nlm.nih.gov/pubmed/8197257

30. Fleck MPA, Louzada S, Xavier M, Chachamovich E, Vieira G, Santos $L$, et al. Application of the Portuguese version of the abbreviated instrument of quality life WHOQOL-bref. Rev Saúde Pública. [Internet]. 2000 Apr [cited Feb 16, 2017];34(2):178-83. Available from: http://www.scielo.br/pdf/rsp/v34n2/1954.pdf

31. Kidney Disease: Improving Global Outcomes. CKD Work Group. KDIGO 2012 Clinical Practice Guideline for the Evaluation and Management of Chronic Kidney Disease. Kidney Int. [Internet]. 2013 Jan [cited Jan 17, 2002];3(1):1-150. Available from: http://www.kdigo. org/clinical_practice_guidelines/pdf/CKD/KDIGO_2012_ CKD_GL.pdf

32. Rick J, Rowe K, Hann M, Sibbald B, Reeves D, Roland $M$, et al. Psychometric properties of the patient assessment of chronic illness care measure: acceptability, reliability and validity in United Kingdom patients with long-term conditions. BMC Health Serv Res. [Internet]. 2012 Aug [cited Feb 16, 2017];12:293.
Available from: https://www.ncbi.nlm.nih.gov/pmc/ articles/PMC3526462/pdf/1472-6963-12-293.pdf

33. Marrero DG. Diabetes care and research: what should be the next frontier? Diabetes Spectr. [Internet]. 2016 Feb [cited Feb 16, 2017];29(1):54-7. Available from: https://www.ncbi.nlm.nih.gov/pmc/articles/PMC 4755457/pdf/54.pdf

34. Lopes AAF. Care and empowerment: the construction of the subject responsible for his own health in the experience of diabetes. Saude soc. [Internet]. 2015 June [cited Sept 13, 2017];24(2):486-500. Available from: http://www.scielo.br/pdf/sausoc/v24n2/0104-1290-sau soc-24-02-00486.pdf

35. Salci MA, Meirelles BHS, Silva DMGV. Primary care for diabetes mellitus patients from the perspective of the care model for chronic conditions. Rev. LatinoAm. Enfermagem. [Internet]. 2017 [cited Feb 16, 2017];25:e2882. Available from: http://www.scielo.br/ pdf/rlae/v25/0104-1169-rlae-25-e2882.pdf

36. Cyrino AP, Schraiber LB, Teixeira RR. Education for type 2 diabetes mellitus self-care: from compliance to empowerment. Interface Comun Saúde Educ. [Internet]. 2009 July/Sept [cited Feb 16, 2017];13(30):93-106. Available from: http://www.scielo.br/pdf/icse/v13n30/ v13n30a09.pdf

37. Gomes AP, Rego S. Paulo Freire: contributions to the changing strategies for teaching medicine. Rev Bras Educ Med. [Internet]. 2014 Sept [cited Sept 13, 2017];38(3):299-307. Available from: http://www. scielo.br/pdf/rbem/v38n3/03.pdf
Corresponding Author:

Líliam Barbosa Silva

Universidade Federal de Minas Gerais, Escola de Enfermagem

Av. Professor Alfredo Balena, 190 sala 200

Bairro: Santa Efigênia

CEP: 30130-100, Belo Horizonte, MG, Brasil

E-mail: ligemeasbh@yahoo.com.br
Received: Jun $13^{\text {th }} 2017$ Accepted: Nov 07th 2017
Copyright @ 2018 Revista Latino-Americana de Enfermagem This is an Open Access article distributed under the terms of the Creative Commons (CC BY).

This license lets others distribute, remix, tweak, and build upon your work, even commercially, as long as they credit you for the original creation. This is the most accommodating of licenses offered. Recommended for maximum dissemination and use of licensed materials. 